\title{
OPERATION PINAFORE
}

\section{THE " CLARA MAERSK" EPISODE. HONG KONG MAY 1975}

\author{
Major M. A. TAGGART, S.R.N., S.C.M., Q.A.R.A.N.C. \\ British Military Hospital, Hong Kong
}

ON Friday evening 2nd May 1975 it was reported over the radio that the Danish vessel "Clara Maersk" had rescued over 3,000 Vietnamese refugees from a sinking ship and was believed to be resuming her journey to her original destination which was Hong Kong, where she was due to arrive on the evening of Sunday 4th May.

Just before mid'day on Saturday, British Military Hospital (B.M.H.), Hong Kong was warned that it was to be the receiving hospital for the survivors requiring medical treatment. Orders were sent to all B.M.H. staff placing them on standby from noon on Sunday. H.M.S. Chichester, the Hong Kong guard ship, sailed at 14.30 hours with two Royal Navy medical teams and a supply of food to meet the "Clara Maersk" and assess the situation. A briefing was held in B.M.H. at 16.00 hours on Saturday, at which it was revealed that refugees of an unspecified number and state of health were to be received in Hong Kong, those in need of immediate treatment being sent to the B.M.H. and the remainder being processed through the, as yet, unopened Princess Margaret Hospital at Lai Chi Kok as a reception centre. Thence those fit enough to travel onwards were to be allocated to three outlying camps - at Sai Kung, Sek Kong and Dodswell Ridge respectively.

A set-up of eleven triage teams was organised from B.M.H. staff, to be under the leadership of the Consultant Surgeon and his immediate deputy the Consultant Dental Surgeon, leaving the senior physicians free. Each team was to consist of a medical officer (as team leader), a nurse (S.R.N. or S.E.N.) and a medical assistant. Triage teams were allocated as follows:-

One to the wharfside at Kwai Chung, two more following later in the event, where the "Clara Maersk" was thought to have applied for a berth (the Maersk Line dock adjacent to Ocean Terminal being unsuitable at this time due to the imminent arrival of Her Majesty The Queen on her visit to the Colony) - one to the Princess Margaret Hospital at Lai Chi Kok-and four to Casualty at B.M.H. The remaining teams were to be held in reserve as relief teams.

The meeting was informed by the Deputy Director of Medical Services (D.D.M.S.) as Chairman that this was in essence to be a civilian exercise but with considerable military assistance as initial back-up and support to augment-by their request-the limited resources of the civil authorities to cope with a refugee influx. The plan at present was that H.M.S. Chichester was due to rendezvous with the "Clara Maersk" at approximately 06.00 hours Sunday morning, when she would be able to signal back more definite information as to the numbers and condition of the refugees. An estimate of potential patients had been put at 200, including 3 or 4 newborn babies and cases of exhaustion and exposure as the majority of refugees had had to be lying about on deck as best they could, the ship having accommodation for only some thirty persons.

The plan at B.M.H. was for clearance of those wards from which patients might be either discharged from B.M.H. or moved to other wards to allow more empty beds 
to be concentrated in certain areas in this emergency. In this way Male Surgical and Medical wards, the Gynaecological ward and the E.N.T./Eye beds on another ward were cleared in the first instance, then the putting up of spare hospital beds and spare ordinary beds would take place, with camp beds being a last resort. The reception of refugee patients was to be at the ambulance bay at the rear of the hospital and then they would be processed through via Casualty, where the triage teams would carry out assessment and urgent treatment, thence taken to the lifts and dispersed to the wards for continuation of treatment and care. Personnel were to be allocated to man the lifts so that one lift was always available at ground floor level should an emergency arise. As far as possible it was hoped that patients only would be admitted, but in the event it proved not only impossible but inhuman to try to separate families that had managed to remain together through such an ordeal. Documentation was to be along the lines and principle of Field Documentation, with changes to usual In-Patient Documentation once patients were settled into their wards.

A platoon of the nearby Royal Hampshire Regiment was to be attached to B.M.H. for security duties and to help with such tasks as stretcher bearing, their help proving to be invaluable.

Contact between those attending the first conference was to be effected on Sunday by telephoning the B.M.H. Administrative Officer at staggered times between 11.00 to 11.30 hours to confirm whether or not the emergency measures were to proceed, by which time H.M.S. Chichester would have made contact with the ship and firm information should thereafter be available at Headquarters Land Forces.

On the Sunday morning H.M.S. Chichester signalled that the total number of survivors was now estimated to be about 4,420 persons. Details of over twenty of the more serious cases were given; two of these were to be picked up by a Royal Air Force Wessex helicopter as soon as the ship was within range, one patient with diagnosis of acute abdomen, and the other a newborn infant of some two days old with septic penis post circumcision.

During the afternoon arrangements were made within the hospital, for back-up supplies, including mattresses (all sizes), linen, pillows, inco-pads, babies nappies and food supplies (including infant feeds). Last but not least an appeal was made that evening for spare clothing to which there was an overwhelming response from the staff and from many people outside the hospital as well-the Welfare Department soon looked like a clothing bring-and-buy stall as a result. Extra beds were being put up and the Children's ward had a number of extra cots, with a supply of extra mattresses without cots or beds which came into their own within twenty-four hours.

Duty rosters were arranged for the nursing staff, so that all nursing members of the eleven triage teams were replaced on their respective wards. Arrangements for this deployment of staff were facilitated by the typhoon emergency expedient of automatic stoppage of days off, nights off and local leave until the situation settled and "Stand Down" could be approved. During the emergency everyone worked as work was available and several of the staff returned to work after a short rest while the acute phase was in progress. All personnel were instructed to report to Reception at 19.00 hours Sunday for a short briefing on the situation as a whole. 
A final conference was convened in the early evening of Sunday at which the D.D.M.S. informed those attending that it was expected the "Clara Maersk" would now dock at approximately 20.00 hours and that figures of expected admissions ranged from 26 to 130 and that the original plan of expecting 180 would be adhered to in these. circumstances. There was only one gangway in use on the ship, the second having been smashed during the transfer at sea, so that one triage team (with back-up if needed) would be sufficient at the dockside and one to be at the Princess Margaret Hospital Lai Chi Kok as planned--both teams to leave at 18.30 hours from B.M.H. having finally checked out their equipment.

The D.D.M.S. said that he planned to go first to Princess Margaret Hospital Lai Chi Kok and thence to Sea-Land No. 3 Wharf Kwai Chung to await the ship's arrival and would thereafter be in radio contact with B.M.H. and Lai Chi Kok and with the three outlying camps, so that an overall picture of the entire operation would be available at any given time. Those attending the Meeting were told that the code-name of this situation was to be "Operation Pinafore"-which did afford a moment of light relief.

The wharfside situation was to be in the charge of a Police Senior Superintendent as that part of the operation was an entirely civilian operation under the aegis of the Hong Kong Government, where the refugees would be medically processed by Hong Kong Government doctors, passed to the B.M.H. triage team if admission deemed necessary and administratively processed by the appropriate Hong Kong Government Immigration and Health Authorities. Initially, all those accompanying patients to B.M.H. were to be taken to the Welfare Department once assurance had been accepted of their relatives' safety and well-being. This scheme only partially worked out due to the extreme anxiety of these people-" accompaniers" wanted to remain that way and thus it happened that lodgers were accepted into the hospital.

At last the "Clara Maersk" docked-taking all forecasters by surprise by coming into harbour at 19.30 hours-and at 19.55 hours the first four ambulances arrived at B.M.H. These contained patients suffering mainly from exposure, dehydration and exhaustion-also two newborn babies with their mothers and one lady in advanced pregnancy who gave birth in B.M.H. afterwards. It was known from H.M.S. Chichester that the refugees had formed their own "Committee of Ten" and that there was organisation among them for priorities of casualties to be disembarked, so those known to require hospital treatment were the first patients to be disembarked. The triage teams at the wharfside were kept busy and did not realise, until told about it, that tenacious Press and television men had climbed up on top of huge containers placed as protection walls and were avidly filming the whole scene.

By midnight on Sunday 4th May, 50 refugee patients had been admitted and by 09.00 hours on Sunday 5th May a total of 100 refugees had been accepted into B.M.H. as patients and 41 as lodgers with relatives who were patients. The majority of these admissions and lodgers had arrived between 20.00 hours on Sunday night and 02.30 hours on Monday morning. The highest total of Vietnamese refugees was noted by midnight on Thursday 8th May, at which time there were 159 refugees in the hospital of whom 119 were patients. This influx of lodgers gave B.M.H. rather a problem of accommodation at one point. The problem was, however, solved by accommodating families (mothers and children) in the gymnasium of the Physiotherapy Department; 
unaccompanied or single women (mothers with ill babies as patients and sisters of patients) in the Handicraft Room and unaccompanied or single men (fathers of ill children, husbands or brothers of women patients) in the Games Area-both the latter on the 15th floor of B.M.H. within the welfare department complex. The extra movement of beds and camp beds entailed in this arrangement was willingly carried out by two further volunteer groups from the Royal Hampshire Regiment.

Feeding difficulties for the lodgers were mainly those of location and timing, once dietary problems had been sorted out by the ever-helpful catering staff, which were resolved by having the mealtimes for all lodgers at the same time as the patients on the wards-but served on the 15th floor in the Up-Patients Dining Room. This solution took some of the load off the ward staff as it did permit a reduction in numbers on the wards at these busy times.

Infant feeds were made up in the Milk Kitchen of the Maternity Unit for 24-hour periods at a time for those wards and areas needing them-such as Children's ward, Isolation ward, the Physiotherapy Department lodgers and the Maternity Unit itself. This proved to be an excellent scheme as it enabled the Children's and Isolation wards to concentrate their staff on nursing care without the commitment of making up infant feeds. This measure was also useful in that it gave the staff of the Maternity Unit a chance to participate in the overall activity - on one occasion in the early morning hours even providing a churn of made-up feeds in a hurry for collection by helicopter for one of the outlying camps.

The wide variety of conditions and of ages of the patients was of considerable professional interest, the latter varying from newborn babes to those people in their eighties and nineties - one of whom was a ninety-six year old blind man. It never ceased to amaze us how all had survived not only the hazardous journey from their homes in Vietnam to the sinking of their first refugee vessel, but also the perilous transfer from it to the larger "Clara Maersk": one crewman later remarked that it was fortunate that the weather was fair and the sea tolerably calm.

Language was a very real problem but, luckily, many of the patients spoke or understood French and some of the others spoke a little English. By dint of linguistic experiment, therefore, a valuable rapport was soon established and those refugees who were able to understand what was being said most willingly translated at all times of day and night for those unable to understand.

As had been suspected most of the patients were suffering from sheer exhaustion, apart from their other conditions which included bilateral conjunctivitis (several cases -some involving whole families), measles, a mild typhoid case, several cases of dysentery and gastro-enteritis, a number of patients with diarrhoea and vomiting and an old lady with hemiparesis from a previous cerebrovascular accident. The surgical conditions included a patient with acute appendicitis (perforation had occurred on 30th April) this was the urgent case evacuated by helicopter from the ship direct to B.M.H. on Sunday afternoon for operation; several patients with injuries incurred during the transfer from one ship to another including traumatic amputation third finger left hand; traumatic amputation 3rd, 4th and 5th fingers of left hand (this patient a female); fractured ribs; laceration upper right thigh; fractured sternum; bilateral fractured ankles; infected laceration left tibial area; traumatic amputation little toe right foot; and bilateral fractured os calcis. Some of their injuries were sustained from falling suitcases, one by 
a falling iron bar and the thigh laceration was due to the patient being momentarily trapped during his transfer between vessels.

As far as could be ascertained not one refugee had been lost in the transfer from one vessel to another-a wonderful feat in itself - but the sorting out and identifying of patients and the tracing of their families or, as in the sad cases of several refugees, which ones were entirely alone or apparently orphaned, constituted a very difficult task. Towards its solution an "Identification Ops Room" was set up in the B.M.H. Conference Room by a team led by the Administrative Officer, consisting of staff from Medical Records Office and clerical staff, which did an interesting job of personnel location. The Hong Kong Government Health and Immigration Authorities had access to those refugees in the hospital and, with the help of several interpreters from various external sources, were able to provide some form of Identification and Authority for Immigration papers for the refugees. Slowly a pattern began to emerge and on Saturday 10th May, 45 Vietnamese left B.M.H. to disperse to the three outlying camps to rejoin relatives or friends or on an allocation basis. They went in two buses and one minibus provided by the Army, with nursing escorts from B.M.H., to Sai Kung (an unforseen problem arose here as some thought they were being repatriated to Saigon because the words are the same in Vietnamese characters and they required firm reassurances on this point), to Sek Kong and to Dodswell Ridge in the New Territories. During the following week further departures took place and by the next Saturday 17th May, 99 refugees had left the B.M.H. On 13/14th May the lodgers had moved out of the Physio-

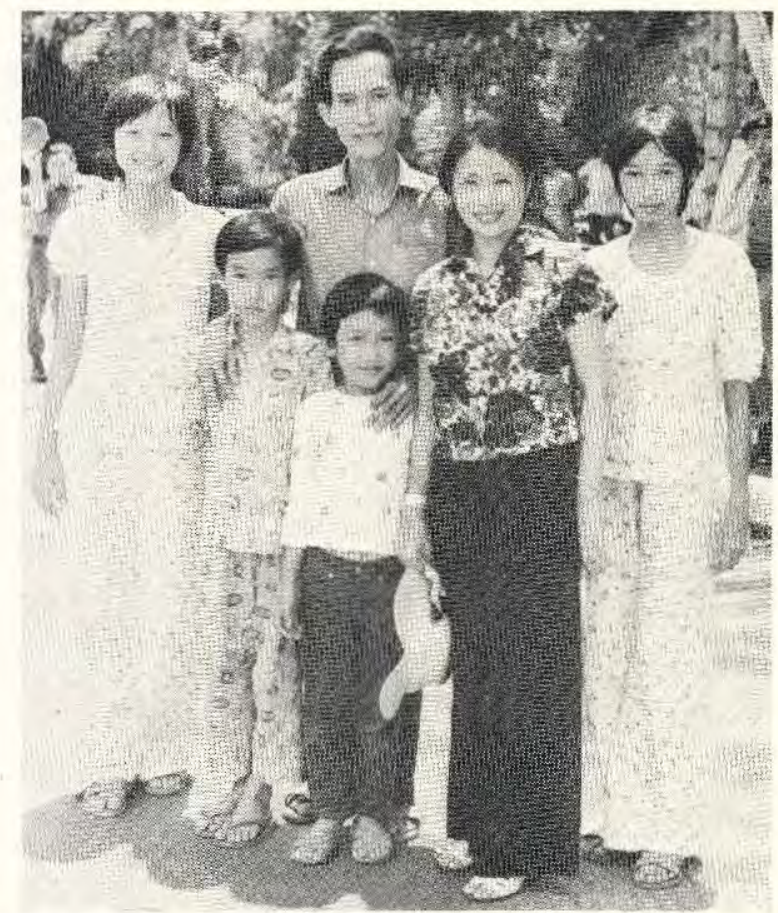

Fig. 1. Taken at Dodswell Ridge-one family that had made it to the end of the line complete as far as was known: but the memories of their journey will always be with them, as the father's still gaunt and strained expression reveals. 
therapy Department gymnasium and the Welfare Department as their numbers had diminished and the remainder were accommodated at one end of the Gynaecological and Male Medical Wards respectively, catering arrangements for them continued as before on the 15 th floor.

During the first week the B.M.H. had been visited by the Commander British Forces, Lieutenant-General Sir Edwin Bramall, accompanied by Lady Bramall, on Wednesday 7th May. A small "Aftermath" conference on the 8th May was chaired by the D.D.M.S. to discuss the whole of Operation Pinafore, to clarify any points arising and to assess the overall effectiveness of the scheme. The numbers of refugees continued to decrease as more were recovering and dispersing to the camps and at the time of writing, 30th May, only five remained in B.M.H.

For those on the nursing side this had been a memorable experience in many ways -not least in that it was a first encounter for most people with refugees and the attendant problems of family identification. There were numbers of stories and impressions, of course, as everyone had their own to recount but the following extracts may help to give an idea of the general situation.

"In Casualty a tearful young woman acting as interpreter as she tried not to think too much of her two young children who had been unable to get out of Saigon and had remained there.

On the Children's ward that Monday morning a scene reminiscent of wartime as forty-four little patients were being nursed on the ward and, when cots and baby cribs ran out, mattresses were brought into service-and still the ward Sister and her staff worked on serenely as if this was a common occurrence.

Again, on Children's ward (where those off-duty and those not required elsewhere congregated like avid foster-mothers at feed-times), a neat move by one Sister twitched a precious new nappy from under another's nose amidst their mutual laughter.

The scene in the gymnasium as an officer and men of the Royal Hampshire Regiment (all volunteers) put up camp beds as a team of off-duty Sisters prepared the room as best they could to provide all " mod Cons " for mothers and children down to disposable nappies and paper towels, then went to the various wards to collect their charges and settle them down.

A lasting impression of one young soldier looking on in embarrassed wonderment as a young mother fed her new baby while she was being moved-bed and all-to another ward, by way of the hospital lift.

In Reception the lone figure of a little boy-name and age then unknown but looking about six years old-unidentified and unable to communicate (and everyone tried: from Vietnamese/French speakers to the official interpreters) but there was nobody who could reach him, so stunned was he by the events of the preceding few days. This story does have a happier ending-he was re-united with his delighted mother out at Dodswell Ridge, but even then he was still a dazed and anxious little boy.

The scene one night on one of the male wards when lodgers had been moved out from the 15th floor and had been given bunk-bed accommodation. One lodger from a lower bunk left it to go to the toilet-his companion in the upper bunk woke up and, 
finding a vacancy, promptly got into the lower bunk. The returning man was most indignant to find his bed firmly occupied and order had to be restored by the night staff and his other companions. Apparently this was an oft-repeated episode and caused much amusement - not least to the night staff, as long as it did not accur too late at night.

On another male ward, the wonderful face of the oldest refugee who was ninetysix years of age and blind, with a face like an etching and still clutching a superbly carved heavy stick-how had he survived such a journey? A clue was given to us when he departed from B.M.H., as he was dressed in white flowing robes with a small white head-dress, still holding his stick-could he have been helped to get away because he was the village headman or some kind of priest?-one wondered ".

Some of the refugees were good artists and several drawings were given to various members of the staff in touching gratitude before they left B.M.H.

One of the two lasting memories of many people who saw such scenes on that Sunday night and Monday morning seems to be the absolute destitution and complete exhaustion of the refugees, most of whom had fled wearing only what they arrived in at B.M.H. many days after their original departure and all that they wanted was somewhere to sleep in safety and peace. Their exhaustion was beginning to resolve after about two or three days in most instances, but regular food and yet more sleep was all they asked.

The other memory was of the pathetic sight of the children, from a few hours old up to the eleven and twelve year olds, most of the latter just sitting in Reception with faces showing a dazed resignation--and stolidly refusing to be parted from their accompanying adults-others crying and some just sitting stunned, as they waited apathetically for the next event in their torn lives.

At the end of a fortnight most of our refugees had departed to the three camps, the organisation of which had by then been taken over by the Hong Kong Government Authorities. Some were to find new homes in other countries including Canada, France, America and Britain, especially if they were more easily employable such as those with extensive clerical experience or artisans. Others would have to wait a while-unless experts in their fields, like the genetics professor. The very young were a burden on their families from the point of view of resettlement in other countries because, from the purely economic angle, such families would have to be subsidised in some form for several years before the youngest members were trained and earning their own livings. Unfortunately the old and the infirm were, as always in the aftermath of any war, unplaceable and unemployable but the family and community feeling of these people had, on the whole, been proved to be so strong that one could only hope that all would be reasonably well for them.

The "Clara Maersk" episode, as it came to be known, was an eye-opener for us all-not only from the hospital side of things as to how contingencies were or were not catered for, what could have been better planned, what part of Operation Pinafore went smoothly -but for the fearful situation in which these people had found themselves and, in so doing, had given us a glimpse of the homeless way of life of any refugee, of the irrevocable displacement of the family unit (total in some cases) and of the prospect of the unknown effect upon the younger refugees. 